\title{
Sink or Swim: Newly Qualified Secondary School Teacher Experiences in Challenging Contexts in Zambia and their Implications for Practice
}

\author{
${ }^{1}$ Madalitso K. Banja, ${ }^{2}$ Sophie Kasonde-Ng'andu, ${ }^{3}$ Akakandelwa Akakandelwa \\ ${ }^{1,2}$ Department of Educational Psychology, Sociology and Special Education, School of Education, \\ University of Zambia \\ ${ }^{3}$ Department of Library and Information Studies, University of Zambia
}

\begin{abstract}
Using qualitative data from a mixed methods study, this paper analyses the experiences of newly qualified teachers in an environment devoid of new teacher support. The findings show that newly qualified teachers in Zambia are not offered support. Usually inadequately trained, they often work in unfriendly environments. While induction and orientation are provided, meaningful support is usually limited. This article has established that schools are failing to provide conducive environments for newly qualified teachers to flourish. Based on the findings of the study, the paper proposes the enhancement of support programmes such as mentorship. It is recommended that newly qualified teachers who have failed to meet expected standards should be provided with academic support to help them achieve competency even as they learn to teach. At the school level authorities should help the new teachers build a sense of commitment to a school and to the profession. Failure to do so has huge implications for the quality of education provided.
\end{abstract}

Keywords: Newly qualified teacher, veteran teacher, working environment, mentorship, school-based teacher support.

\section{INTRODUCTION}

In the United States, Lortie published his pioneering work Schoolteacher (1975), in which he made the point that teaching seemed to be the only profession where the beginner becomes fully responsible from the first working day and performs the same task as a 25-year veteran. Lortie (1975: 26) concluded that: 'compared with crafts, professions and highly skilled trades, arrangements for mediated entry are primitive in teaching.'

Since Lortie's statement numerous other scholars such as Clutterbuck, (1991) have conducted research in the area of mentorship of novice employees. In education, Lortie's findings gave birth to an explosion of interest in the situation of the newly qualified teacher. One way of supporting new teachers in being successful is through mentoring and the first year in teaching, often termed as the induction or transition phase, is recognised as an important segment that has a tremendous impact on a teacher's professional career and personal life (Greiman, 2002), and it is believed to have long term implications for reaching teaching effectiveness, job satisfaction, and career length. The importance of the first year of teaching is well recognised by Archived (2005) cited in Chatora (2008:13) who states that 'as a result of lack of formal guidance and mentoring of teachers, the first year of teaching may be overwhelming for the newly qualified teacher and thus, many find the early years frustrating and discouraging and simply leave the profession'.

Further, Ngalomba (2013) has argued that mentoring after being employed is an essential undertaking for effective preparation of competent and motivated teachers. Another point worth noting according to Ismail-and Arokiasamy (1983) is that mentoring is important for organisational development as it implies workplace learning and leadership principles in career advancement.

From the literature, it is evident that very little is done to provide newly qualified teachers in Zambian secondary schools with school-based support so that they confidently enter the teaching career, stay and enjoy teaching. This school-based support includes mentorship of newly qualified teachers. In Zambia, currently, there is ample evidence that most teachers have not received mentorship because mentorship programmes for newly qualified teachers were virtually non-existent in Zambian schools 
(Malasha, 2009). This is inspite of the fact that there is substantial evidence worldover in the literature of the efficacy of mentorship and that pursuing mentorship for newly qualified teachers can be an effective tool for ensuring quality teachers.

Mentorship has over the years attracted the attention of researchers. Theories about individual behaviour, learning and society influence the design and evaluation of NQT school-based support programmes. Kram (1985) in her Mentor Role Theory, has provided clear theoretical guidance on mentorship as a support system. This theoretical model guided the study upon which this paper is based. According to Kram mentoring functions are those aspects of a developmental relationship that enhance both growth and advancement in an individual. These functions are the essential characteristics that differentiate developmental relationships from other work relationships. These functions can be summarised in two broad categories, namely, career and psychosocial functions.

Career functions serve, primarily, to aid advancement up the hierarchy of an organisation. They serve career-related ends of the junior person by helping him or her learn the ropes of organisational life, gain exposure, and obtain promotions. These functions are possible because of the senior person's organisational rank, experience, and organisational influence. It is this structural role relationship that enables him or her to provide the key career functions of sponsorship, coaching, protection, exposure, visibility and challenging work assignments in order to help a junior colleague navigate effectively in the organisational world.

On the other hand, psychosocial functions are those aspects of a relationship that enhance an individual's sense of competence, identity, and effectiveness in a professional role. Psychosocial functions affect each individual on a personal level by building self-worth inside and outside the organisation. These functions include role modelling, acceptance and co-confirmation, counselling, and friendship. In contrast to career functions, psychosocial functions are possible because of an interpersonal relationship that fosters mutual trust and increasing intimacy. The quality of this interpersonal bond enables the younger to identify with the older and to identify a role model whom the younger would like to become. Through these functions, a young adult launching a career clarifies personal values, develops confidence in a unique style, and can address dilemmas that surface during early adulthood.

Together, career and psychological functions enable individuals to address the challenges of each career stage. Although Kram looked at employees in a business organisation environment, her study has relevance to the present study in that both examine the career and psychological needs of novice employees. Further, Kram's mentor role theory has relevance to the current study in that it deals with the aspect of helping a newly trained teacher find feet in a new working environment and by so doing, enhance his/her job efficacy and competence.

\section{REVIEW OF RELATED LITERATURE}

While studies elsewhere especially in the west have established the importance and necessity of the mentorship of newly qualified teachers, in Zambia literature on the topic is scanty. In agreement, Bolam (1984) when discussing the situation of newly qualified teachers in Britain, argues that external courses however good, were necessarily general and thus peripheral to the probationer's major professional concerns which were to do with their particular pupils, classrooms and schools. Probationers' main source of practical help lay in the school, with colleagues and the headteacher. Considering the many needs that newly qualified teachers have, there is need to help them settle in their new work places because the success of newly qualified teachers depends on how well they are received and integrated into the school. Mentoring for newly qualified teachers is desirable, and different mentoring strategies may be available including one on one mentorship, one mentor handling a group of teachers, in-school mentorship and in-profession mentorship.

Simon and Wardlow (1989) conducted a study and concluded that beginning teachers with mentors were better able to reduce the number and severity of problems they encountered during their first year of teaching, were better at managing their classrooms and preventing problems, exhibited more effective teaching behaviors, and had fewer incidence of disruptive student behavior than teachers without a mentor. Further, mentored teachers were more confident in their abilities, mentioned plans for improvement more often, spoke more freely about their weaknesses, and appeared to be at a higher level of professional development. 
Balthazar (2010) attests to the well-known fact that in education ongoing mentoring has a positive impact on both teachers and students. She adds that when teachers are mentored, the ultimate goal is to impact student learning.

In the context of the study being reported in this paper, support systems refer to the career and psychosocial functions as advanced by Kram (1985) in her Mentor Role Theory.

\section{Methodology}

This section discusses the methodology that was used to collect data. A concurrent mixed methods approach was used for this study. This study utilized a cross-sectional survey with the aim of eliciting detailed qualitative and quantitative information to answer questions on the perceptions of teachers, headteachers and education officials regarding the challenges and coping strategies of NQTs in secondary schools in Zambia.

An interview schedule was used to conduct the interviews. In keeping with qualitative methods, direct quotations have been used to present the findings as they reflect the deep thoughts and feelings of the respondents on what their experiences were concerning their perceptions of the challenges of newly qualified teachers.

The study target population from which the sample was drawn consisted of 5,000 newly qualified teachers based on a recruitment list of names obtained from the Ministry of General Education headquarters in Lusaka, all high school heads of department, all high school head teachers and all Senior Education and Standards Officers, in the Central, Lusaka and Copperbelt provinces of Zambia.

In this study, the researcher employed a combination of probability and non-probability sampling procedures. In terms of non-probability sampling, purposive sampling was used to select eighteen (18) secondary schools, three in each of six districts. Purposive selection of secondary schools was found to be appropriate because the decision depended on the schools with the highest enrolment of newly qualified teachers. In addition, purposive sampling was used to select head teachers, heads of department, Senior Education and Standards Officers and senior officials from the Ministry of General Education.

Probability sampling used a two stage procedure. In the first stage, since the researcher had access to a list of all newly qualified teachers recruited in the year 2011, the study used a single-stage sampling procedure. The population of newly qualified teachers was stratified on the basis of gender and level of education in order to ensure proportionate representation as the population had more males than females and more degree holders than diploma holders.

The researcher targeted 7 newly qualified teachers, 6 heads of department and the headteacher from each of the eighteen schools, six Senior Education and Standards Officers from each provincial education office in the three provinces as well as 6 senior officials from the Ministry of Education headquarters.

The accessible sample of the study was two hundred and seventy (217). This consisted of 92 newly qualified teachers of varying ages and who had been teaching for periods between six months and 24 months, 97 Heads of Department, 15 head teachers, 9 Senior Education and Standards Officers at provincial level and 4 senior officials from the Ministry of Education, Science and Vocational Training and Early Childhood Education national headquarters.

The study targeted newly qualified teachers who had served for a period between 6 and 24 months. Those who had served less than 6 months were considered too raw to give an informed viewpoint on matters under discussion while those who had served more than 24 months were excluded on grounds that they could no longer be considered newly qualified. Ninety-two respondents successfully returned questionnaires, giving a response rate of $73 \%$. The characteristics of newly qualified teachers is shown in table 1 .

The newly qualified teachers were also asked to indicate the subjects they taught in their respective schools. The results show that the respondents were specialised in fourteen different subject areas offered in the Zambian secondary school system. 
Madalitso K. Banja et al.

Table1. Demographic characteristics of newly qualified teachers $(n=92)$

\begin{tabular}{|l|l|l|l|}
\hline Variables & Values & Frequency $(\mathrm{n}=92)$ & Percentage \\
\hline \multirow{4}{*}{ Gender } & Male & 56 & 60.9 \\
\cline { 2 - 4 } & Female & 36 & 39.1 \\
\hline \multirow{5}{*}{ Age } & $19-24$ & 9 & 9.8 \\
\cline { 2 - 4 } & $25-29$ & 56 & 60.9 \\
\cline { 2 - 4 } & $30-35$ & 12 & 13.0 \\
\cline { 2 - 4 } & $36-40$ & 3 & 3.3 \\
\cline { 2 - 4 } & No response & 12 & 66.3 \\
\hline \multirow{2}{*}{$\begin{array}{l}\text { Highest } \\
\text { qualification obtained }\end{array}$} & University degree & 61 & 33.7 \\
\cline { 2 - 4 } & College diploma & 31 & 13.0 \\
\hline
\end{tabular}

Among the heads of department $63(63.6 \%)$ were male while $36(36.4 \%)$ were female. Fifty $(50.5 \%)$ of the respondents had college diplomas while $49(49.5 \%)$ had university degrees. The respondents represented all the seven subject departments in the secondary school system. These had held the position of head of department for periods ranging from less than five years to above 20 years. Their ages ranged from less than 35 years to above 50 years.

As earlier mentioned, all the heads of department of the eighteen schools that were sampled were purposively included in the sample because by virtue of their positions they were directly in charge of day-to-day supervision of classroom teachers. All the head teachers of the eighteen schools that were sampled were purposively selected to be part of the sample because by virtue of their positions they are in charge of all staff and academic matters including ensuring that newly qualified teachers are appropriately inducted into the school and helped to become effective teachers. All the Senior Evaluation and Standards Officers at the provincial offices were included in the sample because by virtue of their positions they are in charge of all matters to do with evaluation and standards at provincial level.

The three research instruments were used to collect both qualitative and quantitative data to provide answers to questions that were raised by the study. Self-administered questionnaires were used to collect data from the newly qualified teachers, heads of department, head teachers and Senior Evaluation and Standards Officers while semi-structured in-depth, face-to-face, one-on-one interviews were conducted with head teachers and key senior officials from the Ministry of Education, Science and Vocational Training and Early Childhood Education. The researcher distributed in person and collected the questionnaires and personally conducted the interviews. Documents were also used to collect data on all relevant aspects of the study. These included policy documents such as Educating our Future; National Policy on Education, educational and professional journals, books, conference speeches, and doctoral theses and master's dissertations as well as websites.

In this study, both quantitative and qualitative methods of data analysis were used considering that some research questions endeared themselves to the use of quantitative methods of analysis, while other questions endeared themselves to the use of qualitative methods of analysis. Qualitative data both from the self-administered questionnaires and the interviews with head teachers and other key informants at the Ministry of General Education were analysed using text and thematic analysis, that is, coding and categorisation of themes emerging from the data, and patterns interpretation. Qualitative data were analysed through categorization and coding of themes as well as item analysis of the questionnaire responses. Descriptive statistics were used to analyse quantitative data. To facilitate this, the Statistical Package for the Social Sciences (SPSS) was used to summarize and analyse the numerical data to generate frequencies, percentages and graphic presentations in form of tables. Data were also analysed by the use of the prestige ranking technique. Using the Statistical Package for the Social Sciences (SPSS) version 20.0. computer programme for windows, frequencies were calculated mainly to generate percentages, while cross-tabulations were conducted to make comparisons between responses given by the different subpopulations.

\section{ETHICAL ISSUES}

The study took into account all measures to ensure compliance with all possible and potential ethical issues of concern. Permission was obtained from all relevant authorities in the Ministry of General Education to conduct this study in secondary schools. Before the respondents were asked to participate they were informed about the purpose and focus of the study and informed consent was thus obtained from all the respondents. This served as a basis for establishing trust between the researcher and the respondents. 
The questionnaires were all anonymous, therefore participants remained anonymous in order to maintain confidentiality and ensure that no harm comes the way of a participant as a result of the research. The data processing was accordingly guarded from exposure to unauthorised persons. Once data was analysed, the questionnaires and the data were safely stored away until such time that they would be discarded so that they do not fall into the hands of other people [including researchers] who might misappropriate them.

In addition, several validation strategies were used to check the accuracy of the data across different data sources. The study further avoided the use of language or words that are biased against persons because of gender, sexual orientation, racial or ethnic group, disability, or age.

\section{Findings AND DisCUSSION}

From the point of view of most of the head teachers, NQTs faced serious difficulties in carrying out their instructional responsibilities in their first few years of teaching. This study found that NQTs did not fully understand the subjects they taught (content knowledge) which includes knowledge of basic and hardcore facts, concepts, theories and procedures within their field of specialization (Shulman, 1986). Furthermore, the study has shown that NQTs had difficulty organising this content knowledge and using it accordingly (methodology). As Koehler (2011) has advanced methodology enables a teacher to know which teaching approaches and strategies fit the content and how to arrange the content for its effective delivery to the learners. From the above it becomes clear that being successful as a teacher requires knowledge of both subject content and pedagogy.

The position of this author is that these NQT handicaps and developmental concerns of NQT can be addressed through appropriate school-based support. The need for support is heightened by the fact that NQTs failed to perform basic functions of teaching such as writing schemes of work and lesson plans. Therefore, while the failure to deliver instructionally can be a factor of many things, the focus of this paper is to discuss the contribution of the working environment to the success of NQTs in their new work places.

The findings of the study indicate that NQTs in Zambia find themselves working in unsupportive working environments. The scenario that NQTs faced of working with little or no cooperation and support from long serving teachers is well depicted in the following sentiment by one of the head teachers:

Old teachers sometimes shun assisting newly qualified teachers to settle in school. They will be isolated and in most cases, they are not incorporated by the old teachers in the system hence they become frustrated and adopt an 'I do not care' attitude.

Another head teacher put it thus:

But, it's not that they cannot perform; they can perform. It is just a matter of adjusting them or adapting them into the system, teaching them, exposing them to the (new) culture of the school. The way they are supposed to conduct themselves and the way they are supposed to teach. Unfortunately, all those areas are not done in most cases.

In support of the above assertions, another head teacher had this to say:

Usually it is one out five that are willing to help the new teachers. It's like they want to see them fail, so that they laugh at them and say they have failed.

This paper utilises Kram's theory to discuss and analyse the unsupportive working environments in Zambian secondary schools and to discuss the negative impact this is bound to have on newly qualified teachers in their quest to become fully fledged and competent career teachers. According to Kram, to achieve this NQTs need to benefit from two types of support, namely career and psychosocial functions or support.

Several scholars (Kram, 1985; Powell, 1997; Ismail, 1983) have advanced that career functions are those aspects of a mentoring relationship that lead to an individual's advancement in an organisation. In other words, the primary goal of career functions is to help a new employee work their way up the hierarchy of an organisation. Regarding the five career functions of coaching, sponsorship, protection, exposure and visibility, and challenging aspects as advanced by Kram (1985), the author established that in Zambian secondary schools, the coaching function is hardly visible. Coaching a novice 
employee, to a large extent entails inducting the novice on the demands of their job, bearing in mind their limited knowledge of the organisational demands. This entails a senior person in the organisation, who knows the politics of the organisation, shares vital information on various aspects of an organisation. Newly qualified teachers are denied the opportunity to access specific proven strategies that enables the NQT perform to expectations.

With regard to sponsorship, it goes without saying that under the environment existing in Zambian secondary schools, a NQT cannot be nominated for any available positions within and outside the school setup. As Kram has argued "a lot of political maneuvering comes to the fore and effective sponsorship makes the difference between whether one gets a promotion at the expense of another or not'.

When it comes to protection, contrary to Kram (1985) findings, NQTs were not protected from undesirable exposure and contact with senior officials of the organisation. On the contrary, as the head teachers revealed, heads of department withheld help from NQTs in order to see them fail in their duties.

With regard to exposure and visibility, in the environment under discussion, the NQT is clearly denied the opportunity to be exposed to important and highly placed people both within and outside the school as they are considered incompetent and therefore denied the opportunity to learn from veterans. Without these opportunities the NQT is equally denied opportunity to be accorded challenging assignments that can expose the novice to difficult and challenging tasks which in turn can help to prepare him/her to perform well as he/she makes progress in their career. Without the opportunity to be exposed to challenging tasks, the NQT is denied access to the massive technical knowledge and skills of veterans and are further denied useful feedback that usually accompanies challenging work assignments given to a novice. In such a support starved environment, a novice cannot gain the needed technical and other skills.

Therefore with regard to the key career functions of a mentor, namely coaching, sponsorship, protection, exposure and visibility and exposure to challenging assignments, it is clear that in the Zambian setup, NQTs are denied all the aspects that are crucial to their adjustment in their new work places and to their career advancement.

In addition to the career functions Kram (1985) and Powell (1997) have analysed psychosocial functions of mentoring that include role modeling, acceptance and confirmation, counseling and friendship or emotional support. These relate to social and networking opportunities. To this effect, $\operatorname{Kram}(1985 ; 32)$ argues that:

While career functions depend on the senior person's position and influence in the organization, psychosocial functions depend more on the quality of the interpersonal relationship.

The need for this psychological support is aptly expressed by Lawson (1992: 166) who records that:

...The provision of experienced teachers as mentors for new teachers in some programmes has stemmed from recognition of the need for personal and social support in the school in addition to technical support. ...the attention given to beginning teachers may mark the beginning of the end for sink-or-swim socialisation with its differential and sometimes damaging effects.

With regard to role modelling, which is dependent for its success on the emotional attachment between a mentor and a mentee, role modeling revolves around two related things; the mentor setting a desirable example through his attitudes, values and behaviour and the novice identifying with and desiring to emulate these attitudes Kram, 1985). In the study under review, both these scenarios were evidently missing. Veteran teachers had neither time nor interest in the professional affairs of NQTs and on their part NQTs opted to leave veteran teachers alone, thereby creating an unhealthy professional standoff.

Regarding acceptance-and confirmation, without the support and encouragement for the NQTs that Kram (1985) has espoused, acceptance and confirmation of the NQT becomes virtually impossible. Without acceptance, a NQT develops the tendency to stay aloof, isolated and watch proceedings from a distance as was reported by the head teachers in the current study. Furthermore, lack of acceptance and a demeaning attitude by veteran teachers towards NQTs is likely to elicit negative feelings of resentment in the newly qualified teachers. With acceptance, however, the NQT is likely to develop confidence in his/her work. It is therefore imperative for schools to help NQTs feel accepted and 
appreciated by welcoming them to their new work stations and providing the necessary guidance and assistance in the first few years of their teaching career.

With regard to counseling, patient, sympathetic listening and feedback from the mentor is required. This enables the NQT to effectively handle all work place issues. In order to survive and counter the organisational pressure that can lead to feelings of alienation and depreciation in self-worth in the novice, the counseling function and partnership is imperative.

When it comes to friendship, social interaction through sharing personal experiences with others becomes unachievable. According to the majority of the fifteen head teachers NQTs worked in an unsupportive working environment that did not welcome and support the NQTs in their work to quickly adjust and adapt to their new working place. Head teachers reported that NQTs were not welcomed and/or assisted in their work by veteran teachers. Head teachers indicated that NQTs did not work well with older or more experienced teachers because the older teachers were 'hostile' to the newly qualified teachers. The study found that these newly qualified teachers consequently felt unwelcomed.

The absence of all these factors discussed above point to the absence of a friendly and welcoming working environment for the newly qualified teachers. Without support from long serving teachers NQTs lacked self-reflection in their work. Head teachers reported that in most cases, NQTs felt sidelined by the long serving teachers hence they became frustrated and relaxed in their work and resorted to working in isolation. While not every NQT expressed frustration with every aspect of the work environment, there was widespread dissatisfaction among NQTs with the inadequate support system.

Therefore, from the point of view of the head teachers, the majority blamed long serving teachers. It appears reasonable to infer that the culture and tradition of a school were key in determining the nature and quality of relationships between NQTs and long serving teachers. Clearly, non-supportive school cultures give rise to feelings of isolation.

The findings of this study show that schools were unwelcoming, and unaccommodative to NQTs. This affected their ability to effectively participate in an integrated fashion in school life and adapt accordingly. From these findings, it is clear that schools needed to assist NQTs to feel accepted. Long serving teachers should position themselves to assist NQTs adapt to their new schools. Schools must provide guidance and assistance to their newest teaching staff and ensure that they are more responsive to the needs of newly deployed teachers and assist them to settle in the school. To achieve expertise in their teaching, NQTs needed support in pedagogy, a need anchored on acquisition of knowledge and skills.

In agreement with Lottie that mentorship has become the preferred choice of new teacher induction, the study sought to establish whether mentorship was accorded to newly qualified teachers. However, it was clear from the responses that technocrats did not even understand mentorship and could therefore not be expected to offer mentorship to newly qualified teachers. For example, head teachers and some senior education officials understood mentoring to be synonymous with orientation as suggested by the following statement from one of the head teachers:

But, they are mentored and talked to; of course they are talked to in colleges. But the DEBS office calls the Head teachers and union leaders to talk to new teachers before they start teaching. If we would do that then we can avoid some of the challenges that we are facing.

In recognising the limitations in the understanding of mentoring of NQTs, one senior education official had the following to say:

...It [mentoring] should not just be done informally where you just get the new teacher, show them around the school, come back and talk a bit on the work culture of the school and all that...

One of the questions HoDs were asked in order to ascertain the nature and scope of mentorship of NQTS was whether there was a policy on mentorship of NQTs at the Ministry of General Education. An overwhelming majority of the HoDs 74 (74.8\%), 62 (67.4\%) of the NQTs and the majority of the headteachers reported that there was no policy on mentorship of NQTs in the MoGE. 
The fact that the majority of the HoDs (84.8\%) and the majority of the fifteen head teachers reported that they had not been mentored on their first appointment seems to agree with the findings of Malasha (2009) who reported that only $20 \%$ of schools in her sample of 10 schools in Chongwe and Lusaka districts were practising mentorship of newly qualified teachers. The findings further strongly suggest that a national policy on mentorship in the MoGE has been missing for a very long time indeed. It appears over the years, NQTs join the system without being mentored considering that the heads of department and head teachers had been in service for a period ranging from less than five years to over 20 years. Further other than the absence of mentorship, other forms of new teacher support like Continuous Professional Development were hardly offered. Where they were they were hardly effective.

\section{ImPlications of the AbSEnCe of SuPPORT for Practice}

While it is acknowledged that support for the teacher such as mentorship has an assortment of benefits, we must not lose sight of the important fact that the ultimate is the good of the learner. Mentoring is not an end in and of itself. Therefore, mentoring is not only necessary for the NQTs; it is essential for the learners as well as they are indirect beneficiaries of it.

The real benefit of support for NQTs lies in the link between the benefits to NQTs and the resultant benefits to learners; for newly qualified teacher support is not for its own sake, but that the teachers improve their performance so that they improve the performance of the learners. The adjustment, the competencies attained and so on, all make sense only if the learners benefit at the end of it all. So while it is true as Rudasingwa $(2013$; 96) writes that 'very little is done to provide young teachers with school-based support so that they confidently enter the teaching career, stay and enjoy teaching', it must be emphasised that the reason for mentorship goes far beyond this; it is ultimately about the learners. This viewpoint is what Shaw (1992:76) is discussing when he asserts that the benefits of mentorship to a school would include 'raising awareness about classroom practice; providing a climate for a discussion about teaching methods and subject content; the enhancement of a variety of school processes, all of which lead to an improved classroom experience for pupils with an ensuing rise in achievement'.

In view of this, the question that begs to be asked is, considering the overwhelming evidence regarding the efficacy of school-based teacher support for NQTs, why is such support for NQTs still lacking in the Ministry of General Education? Further, what are the implications of the absence of this support not just for the NQT, but also for the learner?

\section{CONCluSION AND RECOMMENDATIONS}

The major findings of the study on the question of school-based NQT teacher support reveals that such support was largely missing. The most significant implication of these findings therefore is that NQTs need to be accorded more support than is currently the case because it has ramifications for learning outcomes.

Veteran teachers need to understand that, whether NQTs are willing to learn from experienced teachers or not, they (NQTs) need help because they cannot make it on their own. Veteran teachers have the duty to help the NQTs in pedagogical and moral/social aspects of their work. There is need to bring to an end this sink or swim treatment of NQTs because it has adverse effects on the education system. It is therefore unfortunate that veteran teachers, who were expected to help the NQTs were perceived not to be interested in doing so, hoping instead to see them fail in their work.

On the basis of these findings, the following recommendations are made:

- The Ministry of General Education should seriously consider different forms of school-based teacher support beyond CPD such as mentorship to ameliorate feelings of isolation experienced by newly qualified teachers.

- Institutions of higher learning that train teachers should create mechanisms to follow up on NQT induction programmes in schools to ascertain how well they are fitting into their new work places.

\section{REFERENCES}

Lortie, D. (1975). Schoolteacher: A sociological study. Chicago: University of Chicago Press.

Clutterbuck, D. (1991). Everyone Needs a Mentor. London: Institute of Personnel Management 
Greiman, B. C. (2002). 'Providing professional and psychological assistance for beginning agriculture teachers: The perceptions of formal mentors and novice teachers'. Doctoral thesis. University of Missouri-Columbia.

Chatora, E. (2008) 'Socialisation practices in Zambian Schools'. MEd. Dissertation, University of Zambia.

Ngalomba, S.P. (2013) Mentoring: An essential ingredient in teachers' preparation?

Perspectives from Tanzania. Distance Education and Teachers' Training in Africa (DETA) Conference Abstracts

Ismail- M. and Arokiasamy, L.(1983) 'Exploring mentoring as a tool for career advancement of academics in private higher education institutions in Malaysia'

Malasha, E.C. (2009) 'New teacher Induction programmes and practices in selected high schools of Lusaka province.' MEd. Dissertation. University of Zambia. Lusaka

Kram, K. E. (1985). Mentoring at work. Boston: Scott, Foresman and Company.

Bolam, R. (1984). 'Induction of beginning teachers.' In T. Husen and N. Postlewaite (eds). (1984). International Encyclopedia of Educational Research. Oxford: Pergamon Press.

Simon, S. and Wardlow, G. (1989). "The perceptions of beginning teachers about the value of mentors". Proceedings of the $43^{\text {rd }}$ Annual Central Region Research Conference in Agricultural Education.

Balthazar, C. (2010) Measuring the Impact of Mentoring on Student Achievement. In Reflections" Volume XII, Number 2.

Shulman, L. (1986). Those who understand: Knowledge growth in teaching. Educational Researcher, 15(2), 4-14.

Koehler, V. (1988). Barriers to the effective supervision of student teaching. Journal of Teacher Education, 39(2), 28-35.

Powell, M. A (1997) Academic tutoring and mentoring: A Literature review California Research Bureau Sacramento, CA 95814 CRB-97-011 (916) 653-784

Lawson, A.H. (1992) Beyond the New Conception of Teacher Induction. Journal of Teacher Education 43(3).163-172.

Rudasingwa, E. (2013) School Leadership training, a motivating factor contributing to the provision of highly motivated and competent teachers for Africa. Distance Education and Teachers' Training in Africa (DETA) Conference Abstracts

Shaw, R. (1992). Teacher Training in Secondary Schools. London. Kogan Page.

\section{AUTHORS' BIOGRAPHY}

Madalitso Khulupirika Banja studied Sociology of Education (MEd) at the University of Zambia where he now works as a teacher educator. Currently, he is a Special Research Fellow (SRF) pursuing $\mathrm{PhD}$ studies in Sociology of Education at the University of Zambia (UNZA) themed, Mentoring of Newly Qualified Teachers in Zambian Secondary Schools: An Introspection of Teachers' and Head teachers Perspectives in Selected Districts in Zambia.' Banja has authored two books, Faith of Many Colours: Reflections on Pentecostal and Charismatic Challenges in Zambia (2009) and Teachers as Agents of Pupil Indiscipline (2013) and edited a book of readings titled Selected Readings in Education (2016). He has presented papers at different international fora and has also published a number of articles in peer reviewed journals.

Sophie Kasonde-Ng'andu holds a PhD in Educational Psychology from the University of Zambia where she now works as a teacher educator teaching Educational Psychology at both undergraduate and postgraduate levels. Dr Kasonde-Ng'andu has authored a book on research and has also published a number of articles in peer reviewed journals. She has presented papers at various international fora.

Akakandelwa Akakandelwa holds a PhD in Library and Information Studies. He is a lecturer in the Department of Library and Information Studies teaching both at the undergraduate and postgraduate levels. He has published a number of articles in peer reviewed journals and has presented papers at various international fora. 